https://doi.org/10.46344/JBINO.2020.v09i05.30

\title{
EVALUATION OF THE EMULSIFYING PROPERTIES OF GREWIA SP
}

\author{
'AVBUNUDIOGBA John Afokoghene, OKUNTARAMI Modupe Deborah and ${ }^{2}$ ADJENE Josiah Obaghwarhievwo
}

'Department of Pharmaceutics and Industrial Pharmacy, Faculty of Pharmacy, Delta State University, Abraka, Delta State, Nigeria. ${ }^{2}$ Department of Public and Community Health Sciences, College of Health Sciences, Novena University, Ogume, Delta State, Nigeria.

Email: joadjene@yahoo.com, osgiedeprof@yahoo.com

\begin{abstract}
Polysaccharide gums derived from Grewia spp, a medicinal plant of the Malvaceae family are reportedly useful as excipients in different pharmaceutical formulations. In this study, we investigated and evaluated the emulsifying property of this gum extract by comparing with acacia gum as an emulsifying agent in the formulation of metronidazole emulsion. First, Grewia gum was extracted from pods and characterized. Six formulations of metronidazole emulsion were then prepared from Grewia or acacia gum. Next, the emulsions were evaluated and observed for creaming index, phase separation, viscosity, $\mathrm{pH}$ and organoleptic properties. Study showed emulsion from Grewia gum to exhibit lower creaming index than those of acacia or a combination of both. They however showed higher viscosity than those from acacia or combination of both gums with no apparent change(s) in colour, odour and appearance throughout the period of storage. Also, the $\mathrm{pH}$ value of acacia emulsions proved acidic just as the Grewia gum. The gum showed a $\mathrm{pH}$ of 6.15 with excellent flow property. The study showed the physiochemical properties of the gum to be good and employable in the pharmaceutical industry as a stabilizer, thickener especially when high viscosity is required. Further studies that corroborate this work is recommended.
\end{abstract}

Keywords: Grewia spp, Emulsions, Acacia, Emulsifying agents, Gum. 


\section{INTRODUCTION}

Emulsions are biphasic systems of two immiscible liquids, one of which (the dispersed phase) is finely and uniformly dispersed as globules throughout the second phase (the continuous phase). Since emulsions are thermodynamically unstable system, a third agent, the emulsifier is added to stabilize the system $[1,2]$. The particle size of the dispersed phase commonly ranges from 0.1 micrometer to 100 micrometer. Emulsions are one of the most significant pharmaceutical dosage forms used for poorly soluble drugs. They can be formulated as topical, oral and parenteral dosage forms. Emulsions can vary considerably in viscosity and can present as liquids or semisolids [3]. The pharmaceutical emulsions range from lotions (low viscosity) to creams (high viscosity).

Since antiquity, emulsions have been a form of presenting water insoluble substances for an extended period of time. Recently, it has been used for presenting various intravenous additives and diagnostic agents in $x$-ray examination and pharmaceutical industries [4]. Various substances are used as emulsifying agents to operationally stabilize the droplets formed in the internal phase [5]. Therefore, stability of emulsion could then be used for determining the efficacy of an emulsifying agent. Stability can be estimated by the rate of coalescence of the dispersed globules. The breakdown of an emulsion is usually slow. Means have however been explored to evaluate the stability faster such as adding electrolyte, acids or alkalis causing an increase in the rate of degradation of an emulsion.Grewia spp is a medicinal plant of the Malvaceae family. It is of the genus 'Grewia' and a sub family 'Grewiodes'. The genus 'Grewia' is of 150 species found in tropical and subtropical areas in Africa, Asia and Australia. It is a large flowering genus composed of shrubs and lianas [ 6 , 7]. Grewia spp is locally called "ila-oko" by the Yoruba tribe of Nigeria and Shiboli in Hausa language of Nigeria, also Tiedera by the Mading-Maninka tribe of Ivory coast.

Though, much research has not been done on the plant and very little studies exist on it, its uses among folks vary from nutritional to religious and medicinal purposes. The fruits of the plant are locally used in food as sauces, condiments, spice and flavoring. It is also locally used for medicinal purposes as a febrifuge in treating fever conditions. The healing property of the plant is extracted from the fruits. It is usually used for treatment and religious purposes, mystic and soup with okra taste. Mucilage from the stem of a close specie; Grewia mollis has been used by the people of the middle belt region of Nigeria as a thickener in soups. This mucilage is known as Grewia gum (an intracellular polysaccharide gotten from the stem of Grewia mollis). Grewia gum is used as an excipient to reduce cost of pharmaceutical products [6]. They are high molecular weight polysaccharides which are formed from sugar and uronic units. They are hydrophilic in nature and can be obtained as exudates or extractives from 
the bark of the stems, branches and roots of various plants. Plant families notable for production of gums are Anacardiaceae, Combitaceae, Meliaceae, Rosacea and Rutaceae. Gum form dispersions or hydrocolloids in aqueous medium which suggests that they could be useful in drug delivery. They form gels (hydrogels) on hydration in aqueous medium to produce mesh like network systems which can reduce the diffusional path length of liquid which slow capillary flow of liquid in the system [8].

\section{Aim of Study}

This study investigated the emulsifying properties of Grewia spp gum in metronidazole emulsion. Specifically, the study;

i. Determined the physico-chemical properties of the Grewia spp extract gum.

ii. Prepared metronidazole emulsion using a standard gum 'gum Arabic (Acacia gum)' as an emulsifying agent.

iii. Compared the emulsifying properties of Grewia spp gum with that of acasia gum in metronidazole emulsion.

\section{Materials and Methods}

\section{Extraction of Grewia spp gum}

The Grewia spp pods were washed with water, sliced; after which they were weighed and crushed using a blender. The blended material was boiled with $100 \mathrm{ml}$ of water to obtain a mucilage. The mucilage was then filtered through a muslin cloth to get a viscous and slimy filtrate. The gum was extracted from the filtrate by precipitation method using acetone in ratio of $1: 2$ (i.e $200 \mathrm{ml}$ of the filtrate to $100 \mathrm{ml}$ of acetone). The precipitated gum was collected and dried carefully in hot air oven at $60 \pm 1^{\circ} \mathrm{C}$ till it appears in a cake form. The percentage yield of the gum was calculated as:

\section{Percentage yield $(\%)=\underline{\text { Weight of }}$ the gum}

weight of the fresh pod

Obtained powdered gum was then stored in air tight container for further study.

\section{Identification of Grewia Spp Gum}

A 19 of the gum powder was dispersed in $100 \mathrm{ml}$ of cold water and was allowed to stand for 24 hours.

\section{Organoleptic Evaluation of the Gum}

The powdered gum was examined for organoleptic properties such as colour, odour, texture and taste.

\section{Determination of flow and packing properties of the gum}

\section{i. Determination of bulk and tapped density of the gum:}

A $6.5 \mathrm{~g}$ of the gum was weighed into a $10 \mathrm{ml}$ measuring cylinder and the volume occupied by the gum was recorded. This was done thrice and the average bulk density of the powder was calculated using the equation;

\section{Bulk density $=\quad \underline{\text { Weight of }}$}


Volume

Occupied by Gum

The tapped density was obtained by mechanically tapping the $10 \mathrm{ml}$ cylinder containing $6.5 \mathrm{~g}$ of the gum for hundred times and the change in volume observed. This was repeated twice and the average tapped density of the gum was thus calculated using the equation;

Tapped density
of gum


the ginal volume of
tapping after

ii. Determination of the Angle of Repose of the Gum:

The fixed height cone method was used in which $20 \mathrm{~g}$ of the gum powder was carefully poured and allowed to flow through an orifice of a funnel at a fixed height. The height and width (diameter) of the heap formed were measured and the angle of repose calculated using the equation;

Tan $\varnothing=2$ (height)

Diameter

\section{iii. Determination of Compressibility Index and Hausner's Ratio:}

This was determined from the values obtained from the tapped and bulk density.

\section{Compressibility index $=\underline{\text { Vo-Vf }}$ $\times 100$}

Vo
Hausners ratio $=\underline{V f}$

Where $V_{0}=$ Initial (bulk) volume

$\mathrm{Vf}=$ Final (tapped) volume

\section{iv. Determination of Flow Rate of the Gum:}

A $20 \mathrm{~g}$ powder sample of the gum was weighed into a funnel with a closed orifice, and the orifice was opened and the time taken for the powder to flow through the orifice was recorded. The flow rate was then calculated using the equation;

Flow rate $=\underline{\text { Mass of Gum powder }}$ Time taken

\section{Determination of the $\mathrm{pH}$ of the Gum}

The $\mathrm{pH}$ of $1 \% \mathrm{w} / \mathrm{v}$ preparations of Grewia spp gum was determined using a $\mathrm{pH}$ meter (Fischer, UK).The $\mathrm{pH}$ meter was calibrated with solution of $\mathrm{pH} 7$ buffer at room temperature. Thereafter, the electrode was then immersed into the gum mucilage and the $\mathrm{pH}$ value was read from the meter and recorded.

\section{Determination of Viscosity of the gum}

The viscosity of a $1 \% \mathrm{w} / \mathrm{v}$ preparation of Grewia spp gum was determined using a rotational Brookfield viscometer (NDJ- 1 China) at room temperature. Distilled water was used to calibrate the apparatus. The guard and spindle (spindle 3) were immersed into the gum preparation and was sheared at a speed of $100 \mathrm{rpm}$. The dial reading was taken and the viscosity was calculated using the equation; 
Viscosity $(n)=k \times a$

Where $k=$ factor

$\eta=$ dial reading.

\section{Determination of Swelling Index of the Gum}

A $1 \mathrm{~g}$ weight of the powdered gum was placed in a $10 \mathrm{ml}$ measuring cylinder and was tapped 100 times the volume occupied by the gum after tapping was taking as V1.Distilled water was added to the gum to make up to $10 \mathrm{ml}$ volume and was left undisturbed for 24 hours. A new volume occupied by the gum was recorded as V2 and the swelling index was calculated using the equation;

Swelling index $=\frac{\mathrm{V}_{2}-\mathrm{V}_{1}}{\mathrm{~V}_{1}} \times 100$

\section{Formulation of Metronidazole Emulsion}

Metronidazole emulsion was formulated according to the formula in the Table I by following the dry gum method. A $3.3 \mathrm{~g}$ sample of Grewia spp gum was weighed into a dry mortal, $10 \mathrm{ml}$ of liquid paraffin was measured and added in two to three places while triturating gently to obtained a uniform phase. $7.67 \mathrm{ml}$ of distilled water was measured and added at once and triturated until a white thicken emulsion with a clicking sound was obtained, hence the primary emulsion. $2 \mathrm{~g}$ of metronidazole powder, $0.5 \mathrm{~g}$ of citric acid and $0.1 \mathrm{~g}$ of benzoic acid were weighed separately and $1 \mathrm{ml}$ of propylene glycol was measured and dissolved in an aqueous phase (distilled water). The mixture was added to the preparation and triturated to give a uniform preparation. The emulsion was transferred to a calibrated bottle and was made to $50 \mathrm{ml}$ volume with distilled water. The procedure was repeated for formulation containing Acacia gum (F1), formulation containing Acacia gum and Tragacanth (F3), formulation containing Grewia spp gum and Tragacanth (F4), formulation containing Acacia gum and Grewia spp gum (F5), formulation containing Acacia gum, Grewia spp gum and Tragacanth (F6). The formulations were prepared in duplicate.

Table I: Formulation for the preparation of metronidazole emulsion

\begin{tabular}{lllllllllllll}
\hline Ingredients & F1 & & F2 & & F3 & \multicolumn{3}{c}{ F4 } & \multicolumn{2}{c}{ F5 } & \multicolumn{2}{c}{ F6 } \\
\hline Metronidazole (g) & 2 & 2 & 2 & 2 & 2 & 2 & 2 & 2 & 2 & 2 & 2 & 2 \\
\hline Grewia spp gum (g) & - & - & 3.33 & 3.33 & - & - & 3.33 & 3.33 & 0.33 & 0.33 & 0.33 & 0.33 \\
\hline Acacia gum (g) & 3.33 & 3.33 & - & - & 3.33 & 3.33 & - & - & 3.33 & 3.33 & 3.33 & 3.33 \\
\hline Tragacanth (g) & - & - & - & - & 0.33 & 0.33 & 0.33 & 0.33 & - & - & 0.33 & 0.33 \\
\hline Benzoic acid (g) & 0.1 & 0.1 & 0.1 & 0.1 & 0.1 & 0.1 & 0.1 & 0.1 & 0.1 & 0.1 & 0.1 & 0.1 \\
\hline $\begin{array}{l}\text { Propylene glycol } \\
\text { (ml) }\end{array}$ & 1.0 & 1.0 & 1.0 & 1.0 & 1.0 & 1.0 & 1.0 & 1.0 & 1.0 & 1.0 & 1.0 & 1.0 \\
\hline Citric acid (g) & 0.5 & 0.5 & 0.5 & 0.5 & 0.5 & 0.5 & 0.5 & 0.5 & 0.5 & 0.5 & 0.5 & 0.5 \\
\hline $\begin{array}{l}\text { Liquid paraffin } \\
\text { (ml) }\end{array}$ & 10 & 10 & 10 & 10 & 10 & 10 & 10 & 10 & 10 & 10 & 10 & 10 \\
\hline $\begin{array}{l}\text { Purified water q.s } \\
\text { (ml) }\end{array}$ & 50 & 50 & 50 & 50 & 50 & 50 & 50 & 50 & 50 & 50 & 50 & 50 \\
\hline
\end{tabular}




\section{Assessment of the Emulsion pH}

The $\mathrm{pH}$ of the different emulsion formulations were obtained using the $\mathrm{pH}$ meter (Fischer, UK). The $\mathrm{pH}$ meter was calibrated using distilled water (pH 7) and the $\mathrm{pH}$ of the different formulations at different time interval were recorded at room temperature.

\section{Assessment of Emulsion Viscosity}

A rotational Brookfield viscometer (NDJChina) was used to determine the viscosities of the different preparations. Distilled water was first used to calibrate the viscometer. Each preparation was poured into a beaker and the guard and spindle (spindle $2 \& 4$ ) at the speed of 6 was lowered into the formulation and the dial reading for each preparation was recorded. Each procedure was done in triplicate and the mean values recorded.

\section{Results}

Table II: Physiochemical properties of Grewia spp gum

\begin{tabular}{ll}
\hline Parameters & Results \\
\hline Percentage yield $(\%)$ & 18.64 \\
\hline pH & 6.15
\end{tabular}

Table III: Flow and Packing Properties of Grewia spp Gum

\begin{tabular}{ll}
\hline \multicolumn{1}{c}{ Parameters } & \multicolumn{1}{c}{ Results } \\
\hline Flow rate $(\mathbf{g} / \mathbf{s})$ & $1.75 \pm 0.06$ \\
\hline Angle of repose $\left.\mathbf{(}^{\mathbf{0}}\right)$ & $23.20 \pm 0.19$ \\
\hline Bulk density $(\mathbf{g} / \mathbf{m l})$ & $0.52 \pm 0.01$ \\
\hline Tapped density $(\mathbf{g} / \mathbf{m l})$ & $0.56 \pm 0.01$ \\
\hline Hausner's ratio & $1.07 \pm 0.02$ \\
\hline Carr's index $(\%)$ & $6.95 \pm 1.39$ \\
\hline
\end{tabular}

2020 September Edition | www.jbino.com | Innovative Association
This was carried out by calculating the ratio of the volume of the creamed part (separated part) of the emulsion and the total volume of the product. This was compared for different products.

Creaming index $=$ Height of Sediment $X$ 100

\section{Height of emulsion}

\section{Determination of Phase Separation}

Phase separation of the emulsion was determined by observing visually.

\section{Physical observation of the emulsion}

At weekly intervals for the period of the 4 weeks, the prepared emulsions were observed for physical changes such colour, odour and presence of growth. 
Table IV: Organoleptic properties of the gum

\begin{tabular}{ll}
\hline \multicolumn{1}{c}{ Evaluation parameters } & \multicolumn{1}{c}{ Observation } \\
\hline Visual appearance & Black coloured and coarse \\
\hline Texture & Gritty \\
\hline Taste & Tasteless \\
\hline Odour & Odourless \\
\hline
\end{tabular}

Table V: Viscosity of Emulsion Formulated with different Concentrations of Emulsifying Agents

\begin{tabular}{l|l}
\hline Formulations & Viscosity (poise) \\
\hline F1 & 0.50 \\
\hline F2 & 0.60 \\
\hline & 80.0 \\
\hline F3 & 79.0 \\
\hline F4 & 0.75 \\
\hline & 0.60 \\
\hline F5 & 86.0 \\
\hline & 82.0 \\
\hline F6 & 2.05 \\
\hline
\end{tabular}


Figure I: Comparison of Creaming Index of Emulsions Formulated with different Emulsifying Agents.

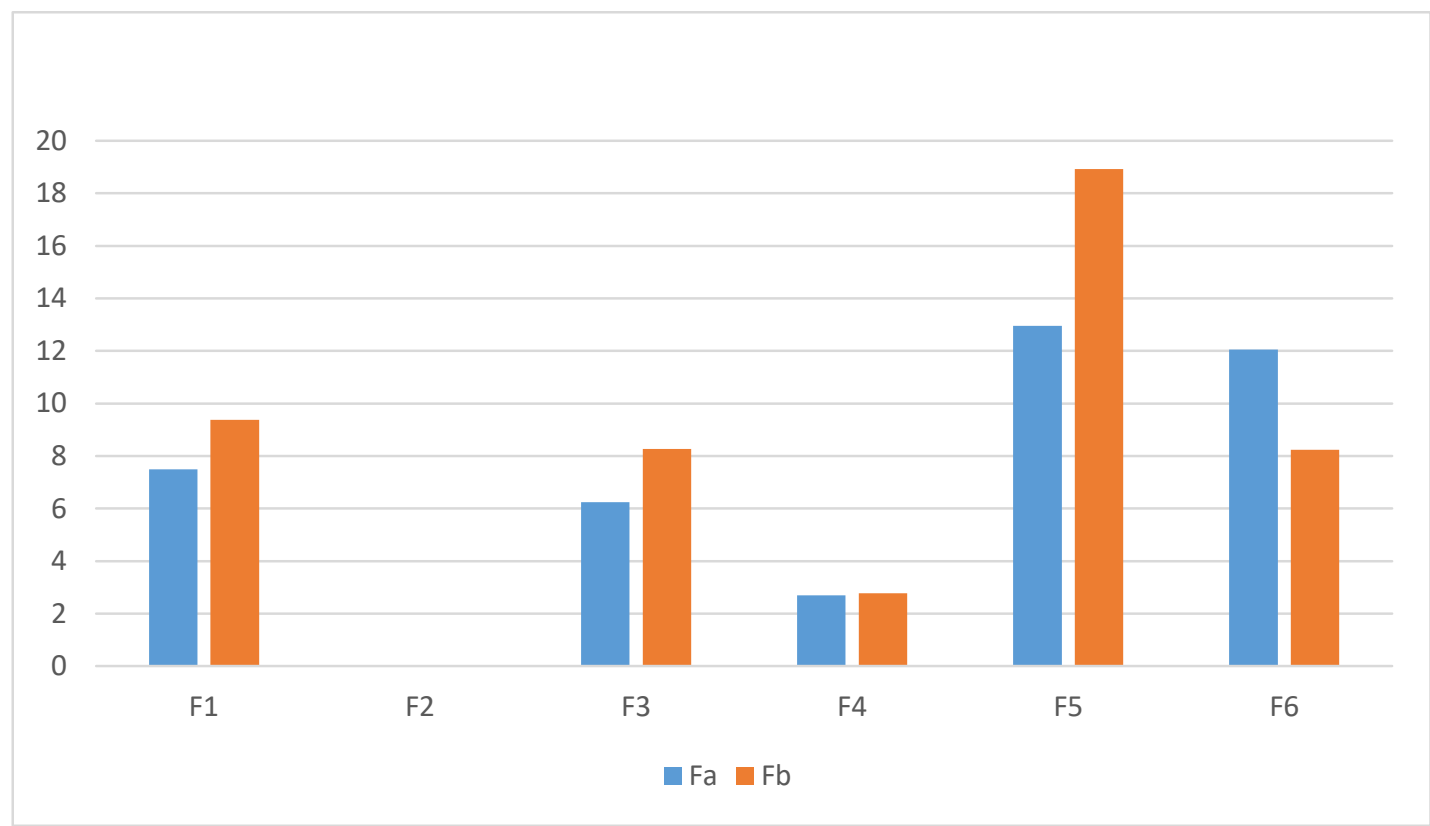

\section{Discussion}

The results for the physiochemical properties of the Grewia spp gum are presented in Table II, the $\mathrm{pH}$ of the gum was 6.15 which shows the gum is weakly acidic and can thus be used as an enteric polymer for protecting acid labile drugs. The swelling index of the gum was observed to increase with the volume of the gum with increase in time. The swelling index showed the gum has good water uptake capacity and can be used in controlled drug delivery system permutations. The results for flow rate, bulk and tapped density, Hausner's ratio and Compressibility ratio values for Grewia spp gum are shown in Table III. The angle of repose value showed the gum has excellent flow properties. The Hausner's ratio and Carr's index also indicate that the gum powder has an excellent flow property and which can afford good quality of the product as it facilitates dose uniformity.

Also, the visual appearance, texture, taste and odour of the gum gave the following results as shown in Table IV. On allowing the gum to stand for 24 hours, a viscous gel like dispersion was obtained showing the presence of a gum.

The $\mathrm{pH}$ of the emulsion formulated were acidic. The variation in the $\mathrm{pH}$ of the emulsion after some days showed that the longer the storage of the emulsion, the higher the $\mathrm{pH}$ value hence decrease in acidity. The $\mathrm{pH}$ of the emulsion prepared with Grewia spp gum were higher than those prepared with Acacia. From table $\mathrm{V}$, emulsions formulated with Grewia spp gum had lower pH (i.e. pH more acidic), this could be attributed to the fact that the gum is acidic (weak acid with a $\mathrm{pH}$ of 6.15) and also the preservative used (benzoic acid is also 
acidic). Thus, though the formulation is acidic, bacteria growth is unlikely to occur due to the presence of compatible acidic preservative. All formulations showed no colour change, no change in appearance or odour at the end of onemonth period. This can be attributed to the presence of a strong compatible preservative (benzoic acid) in the formulation. However, emulsion containing Acacia had separated at the end of the second week and coalesce at the end of the third week. The presence of coalescence in the formulation is an indication of instability. The emulsions formulated with Grewia spp gum were more viscous, this is due to the highly viscous nature of the gum. The emulsions formulated with Acacia had the lowest viscosity. Thus, formulations with Grewia spp gum will have slower settling time which will enhance the formulation stability and also dose uniformity.

From figure I, Fl (containing Acacia) and F3 (containing Acacia and tragacanth) had high creaming index as the volume of sediments increased progressively during the period of storage compared to other formulations containing Grewia spp gum. F5 (containing Acacia and Grewia spp gum) and F6 (containing Acacia, Grewia spp gum and tragacanth) had a very high creaming index. This could be due to incompatibility of the emulgents. F2 (containing Grewia ssp gum) and F4 (containing Grewia spp gum and tragacanth) present as good emulsion and had better stability although the formulation containing combination of Grewia spp gum and tragacanth had low level of sediments. F4 still had better stability properties as they can attain stability faster.

\section{Conclusion}

In this study, Grewia spp gum was successfully extracted from freshly collected pod of Grewia spp. The study showed the physiochemical properties of the gum to be good and employable in the pharmaceutical industry as a stabilizer, thickener especially when high viscosity is required. The gum was used as an emulsifier for metronidazole as the model drug for this study and its emulsifying property was comparable to that of Acacia gum. In comparison to Acacia gum which is a standard gum, Grewia gum yielded better emulsifying properties. The gum also yielded better emulsifying properties when used alone rather than in combination with Acacia. Also, Emulsions containing Grewia gum (F2) yielded emulsions void of sediment.

\section{References}

1. Barkat Ali Khan, Naveed Akhtar, Haji Muhammad Shoaib Khan, Khalid Waseem, Tariq Mahmood, Akhtar Rasul, Muhammad Iqbal and Haroon Khan (2011). Basics of pharmaceutical emulsions. African Journal of Pharmacy and Pharmacology, 5(25): 2715-2725.

2. Chattopadhya S, Singhal RS, Kulkarni PR and Sonic PL (1997). Microencapsulation of vanillin using Acacia nilotica gum. Journal of Scientific and Industrial Research, 56(2): 109-110. 
3. Okafor, IS, Chukwu A. and Udeala K (2001), some physicochemical properties of Grewia gum. Nigeria Journal of Polymer Science and Technology, 2(1): 161-167.

4. Panda, D. S. (2014). Studies on gum of Moringa oleifera for its emulsifying properties; J Pharm Bioall Sci.; 6: 92-6.

5. Martin, M. R. (1991). The theory and practice of industrial pharmacy. In: Lachman L, Lieberman HA, Kanig, J. L, editors. 3rd ed. 4th Indian reprint. Bombay: Verghese Publishing House; pages 23, 4-7.

6. Elijah I. NEP, Barbara R. Conway (2011). Evaluation of Grewia polysaccharide gum as a suspending agent. International Journal of Pharmacy and
Pharmaceutical Science, 3(2): 168173.

7. Lowry II P, Pilipson P, I Schatz G, Wahlert $\mathbf{G}$ (2013). The lianescent species of Grewia (Malvaceae SI, formerly tiliaceae) extracted from https://www.researchgate.net/pub lication/263854540 on 18/03/2019.

8. Modupe O. Ologunagba, Sanyog Jain, Kaushik Thanki, Sarasija Suresh, Sharon Furtado, Chukwuemeka P. Azubuike, Silva B. Olanrewaju (2017). Extraction and characterization of the gum exudate of Anacardium occidentale for its potential as an excipient in drug delivery systems. Tropical Journal of Natural Products Research, $1(2)$ : 76-83. 